\title{
DOS EPIGRAMAS FUNERARIOS AL PERRO DE ZENÓN (P. Cairo Zen. 59532) Edición y Estudio
}

\author{
Rodolfo P. Buzón \\ CONICERT - UBA - UCA \\ Pablo A. Cavallero \\ UBA - CONICET
}

Es nuestra intención, en esta ponencia, presentar un estudio filológico y ecdótico de un par de epigramas anónimos, articulados como unidad y dedicados a un lebrel de nombre Taurón, que salvó la vida a su amo Zenón. Antes de llegar a la edición, traducción y comentario del texto, consideramos necesario referirnos brevemente al género epigramático y a su evolución hasta el período helenístico, y en especial a los epigramas paralelos y a los dedicados a animales.

Según Marion Lausberg ${ }^{1}$, el epigrama como forma poética puede remontarse por lo menos hasta el $\mathbf{s}$. VII y quizás hasta fines del s. VIII a.C., por una referencia de la IIfada (VII 89-90). Los documentos arqueológicos del s. VII muestran el uso de versos en monumentos y particularmente del hexámetro, metro que Lausberg no considera influjo necesario de Homero. En ese siglo ya hay epigramas fúnebres y votivos; son generalmente muy breves, el más extenso tiene seis versos. Pero gradualmente el poema tiende a adquirir mayor extensión. Ya en el período helenístico los epigramas preferidos son los de cuatro versos, aunque los hay también de seis a ocho versos, y algunos tengan hasta treinta o más versos; es raro aquel que esté formado por un solo dístico. Esta mayor extensión parece característica de Egipto y de Creta. Además, si bien en la época arcaica la extensión mayor significaba únicamente un honor especial, con el correr del tiempo los poetas ampliaron las composiciones porque les ofrecian la ocasión para desarrollar su capacidad poética.

Lausberg señala ya en el epigrama fúnebre arcaico dos partes básicas: la "presentación", informativa y objetiva, que ofrece formulariamente el nombre del muerto y algo sobre su persona, y luego los "pormenores", más específica, que incluye el elogio del muerto, el lamento por su pérdida, cuál era su areté y cómo la alcanzó. El epigrama sepucral tendría como finalidades el ampliar o adornar la simple prosa, transmitir un especial mérito del difunto y expresar el encomio.

Por otra parte, para Lausberg -quien centra su estudio en las composiciones formadas por un solo dístico- la relación con la elegía, género ya formado en 560 a.C., se limita a giros lingüísticos y al tema de la areté ${ }^{2}$, pero niega que la elegía se haya generado con intención funeraria. Coincide en esto Gentili cuando sostiene que el hexámetro de las inscripciones fúnebres más antiguas contradice una conexión directa con el eppivos elegíaco y votivo ${ }^{3}$. Sin embargo,

1. Cf. Lausberg, passim.

2. Se funda en P. Friedländer - H.B. Hoffeleit, Epigrammata. Greek Inscriptions in Verse. From the Beginnings to the Persian Wars. Berkeley - Los Angeles, 1948.

3. Cr. Gentili, passim. 
Gentili observa que a fines del s.V, aunque ė $\pi i ́ \gamma p \alpha \mu \mu \alpha$ fuese toda inscripción sobre un objeto, si estaba en dísticos también podía llamarse $\varepsilon \hat{\lambda} \varepsilon \gamma \varepsilon \hat{\imath}$ iov. A fines del S. IV aparecería el uso literario del epigrama, término que entonces designó también a la poesía breve no epigráfica, convivial, de tono variado, que refiere ocasiones de la vida social y privada, y que por lo general se escribe en dísticos, pues Cameleonte llama epigrama al poema convival en hexámetros, en tanto Plutarco reserva para el

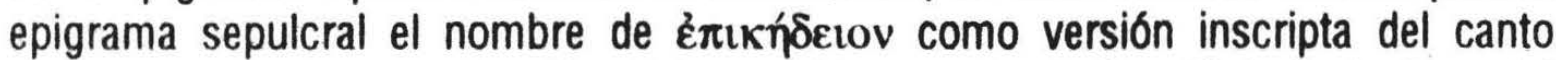
ceremonial de lamento. Gentili señala también que el epitafio utilizó desde fines del s. VI metro, léxico y estilo líricos de modo no excepcional, que usó léxico de opp̂vos solamente cuando el texto estaba puesto en boca del muerto y que tardiamente se estructuró como una elegía breve entre lo trenódico y lo narrativo adoptando términos de lamento. El gran cambio en la evolución del epitafio habría ocurrido durante el s. IV a.C., cuando el influjo de la tragedia y de la filosofía provocan en él una ampliación de temas, motivos y recursos lingüisticos, que significan un desarrollo literario del arcaico epigrama desnudo, simple y condensado, y generan también una impostación dramática al sugerir la presentación del monumento como una persona y del muerto como sujeto parlante.

En cuanto a métrica, Gentili opina que la adopción del dístico en lugar del hexámetro permitió al epitafio liberarse de la sujeción lingülstica a la epopeya, acceder al lenguaje de la elegía, a la variedad temática, al tono coloquial; el yambo habría sido adoptado solamente cuando el nombre del difunto o el del dedicante no se adaptaban al dáctilo. Lo cierto es que los epigramas, incluso los fúnebres, conservan aún en el período helenístico el influjo del dialecto épico y del dórico; de ahí que Hopkinson ${ }^{4}$ señale que la lengua del epigrama es una amalgama artificial que no responde al habla real de ninguna región, que yuxtapone a epicismos y dorismos formas áticas equivalentes $(\kappa \varepsilon / \kappa \alpha)$, lengua que se torna insegura por las substituciones de los escribas.

El carácter general del período helenístico, período al que corresponde el par de epigramas que nos ocupa, genera también cambios en los rasgos del epitafio: al interés por la virtud en general se añade el interés por lo individual y lo cotidiano, hasta entonces considerado indigno de una inscripción; se da mayor espacio al fluir del lamento de los deudos; se busca despertar la simpatía del lector, en especial cuando el difunto era joven tema que aparece ahora con gran frecuencia. La extensión se hace mayor y también evoluciona el estilo: epítetos, paráfrasis, imágenes, expresiones patéticas, profusión de palabras son sus rasgos más salientes. "El epigrama fúnebre de carácter literario, sobre todo, tiene precisamente que ofrecer más que informaciones sencillas en formas tradicionales y es más fácil conseguir algo 'interesante' por medio de un desarrollo poético, mediante una mayor minuciosidad de contenido y un perfeccionamiento estilístico" 5 .

Por otra parte, en Grecia existía la costumbre de erigir tumbas a los animales domésticos, especialmente a los perros, muy queridos por sus dueños ${ }^{6}$,

\footnotetext{
4. Cf. Hopkinson, p. 274.

5. Cf. Lausberg, p. 148.

6. Cf. Gorteman, pp. 118-119.
} 
y colocar en ellas lápidas con epitafios ${ }^{7}$ Según Herrlinger ${ }^{8}$ los testimonios demuestran que es el helenismo el creador del epigrama para animales, y menciona como causas aquellas que ya señalamos: la concepción de la poesía como reflejo de la realidad cotidiana, la inclinación hacia lo pequeño, la valoración de lo individual y de los afectos personales, el halago de la propia vanidad y la gran gran difusión de la poesía como bien general, que provocó un incremento de la poesía fúnebre y la introducción del tema de los animales como variedad lúdica.

Lo cierto es que, según señala Herrlinger, en el siglo IV el animal comienza a hacerse más presente en el pensamiento griego; a la vez se acrecienta el ejercicio de la cacería, de modo tal que adquieren significación especial el lebrel y el caballo de caza. El no poseer perro es considerado indicio de pobreza, y se valora a tal punto la fidelidad, el apego, la sabiduría y la integridad de los animales por oposición a la degeneración del ser humano, que empieza a hablarse del "derecho de

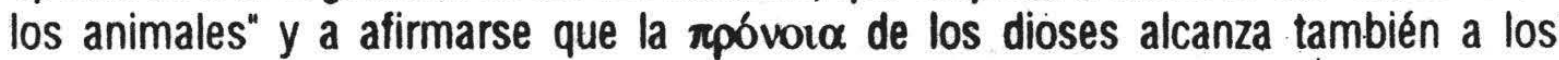
$\alpha \lambda_{0} \gamma \alpha \zeta \hat{\alpha} \alpha$. No debe extrañarnos, pues, que la integración del animal a la vida del nombre haya dado lugar a que aparecieran representaciones de ellos como sugiere el epigrama votivo de Macedonio (A.P. VI 175), ni que se los incorporara a las lápidas de tumbas de seres humanos, ya tallados, ya en los versos de los epitafios. Esto constituye el antecedente directo de las tumbas para animales y de los epigramas a ellos dedicados. En ellos debemos distinguir aquellos que hacen una simnple mención de algún animal, de aquellos que se centran temáticamente en alguno de modo particular. La Anthologia Palatina ${ }^{9}$ y la Anthologia Latina ${ }^{10}$ nos ofrecen gran variedad de ejemplos. De toda esta gama de epigramas votivos, demostrativos, satíricos y fúnebres nos interesarán especialmente el de Antípater (A. P. IX 417 = Guirnalda de Filipo, Antipater $\cdot \mathbf{L X X}$ ), centrado en la muerte de un perro sediento, el $X$ de Anite (HE, p. 37), que se ocupa de una perra mordida por una

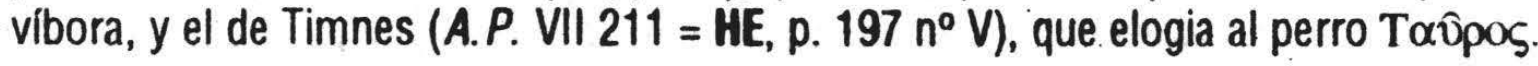

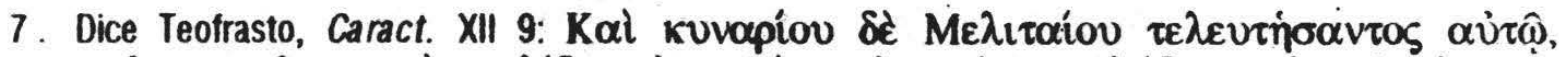

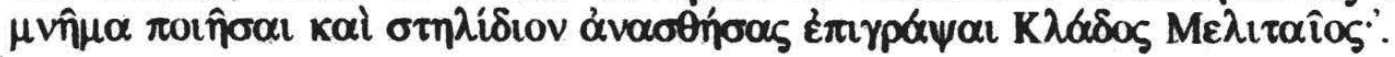

8. Cf. Herrlinger, passim.

9. La alusión a la imagen de un perro que parece real (Macedonio, VI 175) o la de un cachorro en el monumento de su ama (Antipater, VIII 425), la simple mención de perros (Ion, VII 44; Anón., VII 338; Adeo, IX 303; Sátiro, X 11; Leónidas, IX 337; Tiberio, IX 370; Lucilio, XI, 194), la assimilación del perro al cínico (VII 115 y 116) y a Orión o Sirio (X 12), a como metamorfosis de un estratego (XI 360), escenas diversas como el perro ofrendado pero vuelto a casa (Macedonio, VI 176), el perro que se lanza al mar para cazar delfines (Filipo, IX 83), la perra que da a luz mientras caza un ciervo (Antipater, IX 268), otra perra operada para partir (Filipo, IX 311), un perro de caza que muere a causa de la sed, perros que ahuyentan a un lobo (Ericio, IX 558), perras que ladran mientra un lobo atrapa a una cabra (Teócrito, IX 432), una alusión a Argos, el perro de Odiseo (XI 77), como asi también referencias a otros animales, liebres atrapadas por perros (Germánico, IX 17 y 18), liebre que escapa de un perro y cae en [los tentáculos] de un pulpo (Isidoro Egeato, IX 94) o en un perro marino (Anón., IX 37), un jaball (XV 51).

10. Aporta tambien curiosas variantes: epigramas qe se ocupan de elefantes $(186,187)$ o mencionan alguno $(348, v$. 11), un epigrama sobre peces $(286)$, otro acerca de un jaball domesticado (287) y otro más en torno de Pegaso (383), alguno sobre leopardos que cazan perros (355) y otros que simplemente mencionan animales, un cerdo (380), un jaball (379), un lobo y una oca (381) o jabalies, cabras, ciervos y caballo a la vez (302), a los que podriamos añadir los perros de caza esquivados por ladrones en Crinágoras XXX (Guirnalda de Filipo, p. 216) 
La iniciadora de esta poesía dedicada a animales parece haber sido Ánite (acmé 300 a.C.), creadora de la bucólica arcádica, que desde la actitud sentimental de la lírica dórica del Peloponeso, vinculó estrechamente el animal con el paisaje, seguida por sus contemporáneos y coterráneos Nicias y Mnesalques. Es esta una poesía aristocrática en cuanto se destina a una clase social próspera, por el objeto del poema, y elegante por el estilo que requiere. De toda la epigramática referente a animales, parecen haber tenido finalidad funeraria especifica y concreta poemas centrados únicamente en perros y en caballos.

En los papiros hallamos muchas veces expresiones de preocupación por los animales domésticos, preocupación guiada en algunos casos, como el de cerdos o bueyes, por interés pero no por eso menos cierta; en vez, era afecto, lo que los habitantes del país del Nilo sentían por caballos y perros ${ }^{11}$.

El epitafio para el lebrel Taurón, es decir, para la tumba de un animal, tiene, también la característica de presentar dos poemas paralelos, uno escrito en dísticos y otro en yambos, ambos unidos por ǒ̀ $\lambda \lambda_{0}$. La costumbre de presentar dos poemas paralelos parece remontarse al Poliandrión de Potidea, monumento ático en homenaje a los caídos en 432 a.C. ${ }^{12}$. Durante el siglo IV se habría iniciado su aplicación a particulares ${ }^{13}$. Segün Marion Lausberg, los epigramas paralelos contienen un texto relativamente extenso, cada sector se dedica a destacar algún aspecto, de modo que uno y otro se completan mutuamente. Hoy se rechaza casi unánimemente que tales varsiones sean obra de poetas diferentes que compiten entre sí. En esos casos algunas veces los dos textos juntamente con ǒ̀ $\lambda \lambda \lambda_{0}$ eran grabados en la piedra, como en Kaibel, Epigr. gr. 550 (s.II-III) ${ }^{14}$. La opinión general es que el autor ha de haber sido un poeta alejandrino. Un argumento en favor de esta tesis es que un poeta local no habría necesitado aclarar en la dirección:

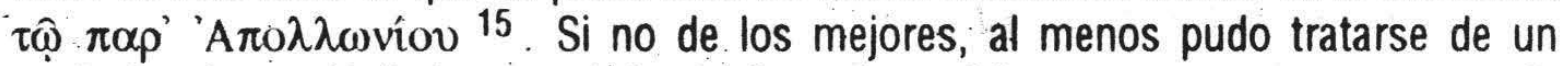
profesional que sin duda conocía la técnica epigramática, pues no parece tratarse de un mero ejercicio literario.

La hoja de papiro que contenía las dos composiciones fue hallada entre los documentos del archivo de Zenón, que fuerón descubiertos en Filadelfia, EI Fayum, por campesinos egipcios poco antes de la primera guerra mundial y vendidos en lotes pequeños a distintos interesados, para obtener así una mayor ganancia. El número de papiros supera ampliamente los dos mil y están fechados entre los años 261 y 239 a.C.; alguno podría ser incluso del 230/29 a.C. Ese sería el terminus ante quem.

Zenón, hijo de Agreofón, era originario de Cauno, en Caria, es decir, uno de los tantos griegos de Asia Menor que afluyeron a Egipto después de la conquista de Alejandro Magno. Durante los primeiros tres o cuatro años de su carrera actuó

11. Cf. Gorteman, pp. 101-120.

12. G.V. 20, Pfohl 94, Hansen 11.

13. G.V. $1888 \mathrm{ss}$.

14. Para la presencia unida de dísticos y yambos en lápidas cf. Kaibel $325,462,502,546$. Hiller von Gaertringen señala como un precedente de esta costumbre temprana, la unión de una inscripción votiva con la inscripción yámbica de un artista, como en Röhl, Imag. XXXVI 3 (s. VI), y la inscripción del Coloso de Rodas del 292 (A. P. VI 171 y Preger, Inscr. gr. metr. 280). 
como agente comercial de Apolonio, ministro de finanzas de Ptolomeo Filadelfo y de Ptolomeo Evérgetes. Estaba encargado del comercio con Palestina y Siria. Luego pasó a integrar la secretaría del ministro, a quien acompañaba en sus distintos viajes. De su vida privada casi nada es lo que sabemos, salvo que tuvo un hermano en Egipto y que enfermo durante largo tiempo. Esa debe de haber sido la razón por la cual pasó a desempeñarse como administrador de un amplio dominio, en el nomo Arsinoíta, que Apolonio habla recibido de Ptolomeo II en calidad de $\delta \omega \rho \varepsilon \alpha ́ \alpha$ (de don, en esta época a título precario), en recompensa por sus servicios. El primer administrador fue un cierto Panácestor, al parecer también de Caria como Zenón y

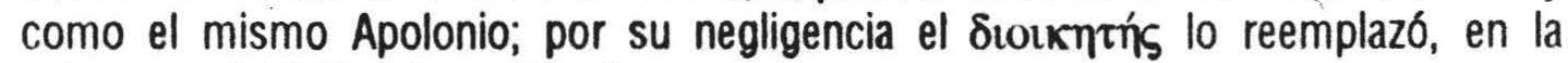
primavera del 256 a.C., por Zenón.

El nuevo administrador, no desprovisto de cultura y amante de la buena mesa, se dedica, entre otras actividades, a la caza y se interesa por los perros ${ }^{16}$ Una prueba de ello lo constituyen los dos epigramas que nos ocupan. Según lo que leemos en la primera de las composiciones, la lucha tuvo lugar en 'Aporvoïtms (v. 5); por lo tanto, ello debe de haber sucedido después de la llegada de Zenón El Fayum en calidad de administrador, es decir, después del 256 a.C.; tenemos también asi un terminus post quem para su redacción. Para Wilcken es altamente probable que los epigramas hayan estado destinados a ser grabados en una lápida y que lo hayan sido realmente.

Señalemos, finalmente, que si bien Gorteman cree inverosímil que el hecho narrado en los epigramas haya acaecido realmente, se puede aducir en favor de su veracidad que, como ya dijimos, se conservan testimonios del interés de Zenón por la caza y, además, que parece improbable que haya solicitado la composición de un epitafio que aludiera a un hecho irreal ${ }^{17}$.

\section{TEXTO}

Para la edición partiremos del texto tal como lo da D.L. Page en su Greek Literary Papyri, I 460, y anotaremos en el aparato las variantes y conjeturas de las restantes ediciones. Si bien Page indica como editio princeps la de Edgar, P. Cairo Zen. IV 59532, la primera edición ha sido en verdad de Edgar, pero en los Annales du Service de l'Antiquité de l'Égypte.

En el aparato utilizamos las siguientes abreviaturas:

E ..............editio princeps.

Pap.

$p^{1}$

$\mathbf{P}^{2}$

P-B

H P. Cairo Zen. IV 59532 GLP. ..Further... .Powell-Barber Herrlinger

Utilizamos los siguientes signos:

[ ] .............laguna

I! corrección en el orignal inserción por encima del renglón

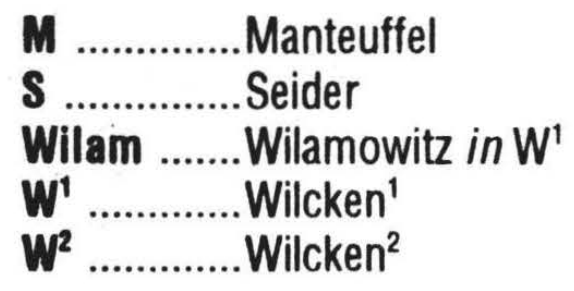

16. ct. Préaux, pp. 35-36.

17. Cf. Page, Further ..., p. 457 y Powell-Barber, p. 108. 
Los puntos entre corchetes indican el número estimado de letras perdidas 0 borradas; los puntos fuera de los corchetes, letras mutiladas o ilegibles; los puntos bajo las letras indican que se trata de una lectura dudosa. La iota adscripta indica que se la encuentra así en el texto; la iota suscripta, que en el texto está omitida.

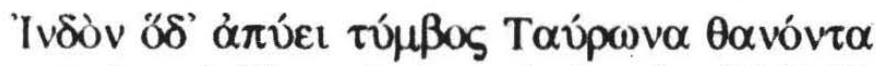

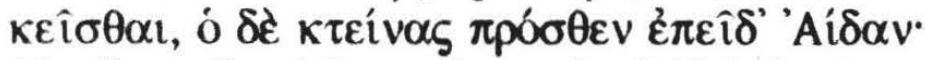

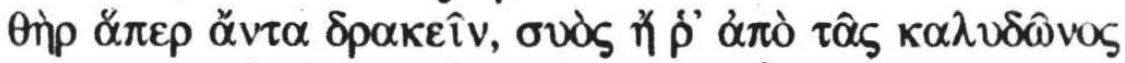

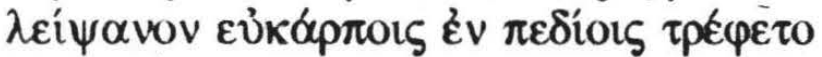

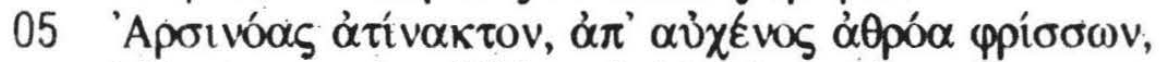

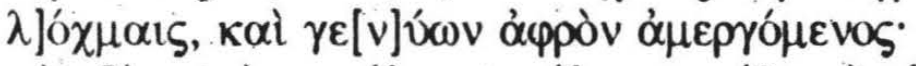

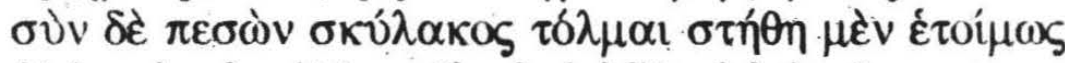

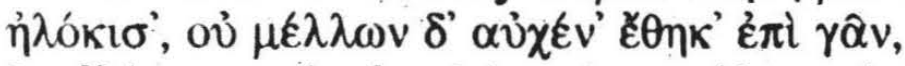

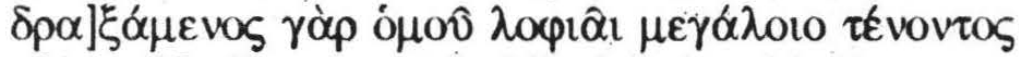

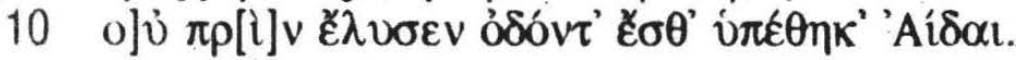

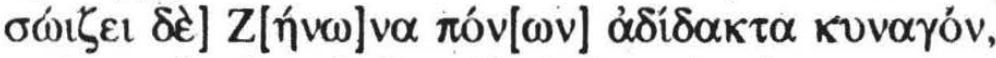

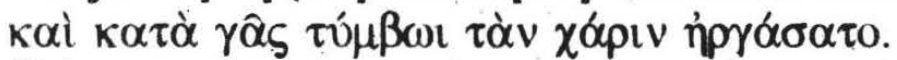

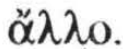

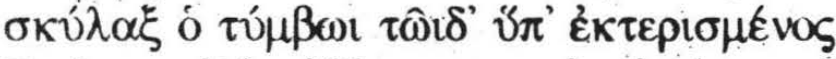

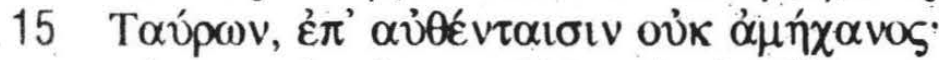

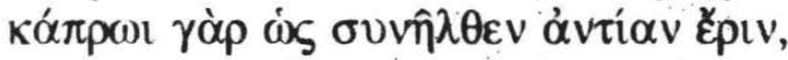

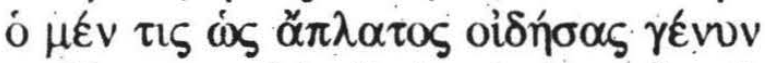

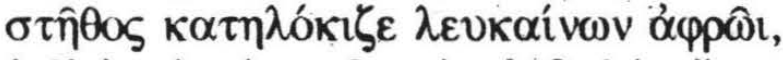

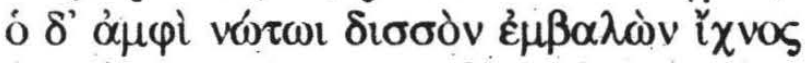

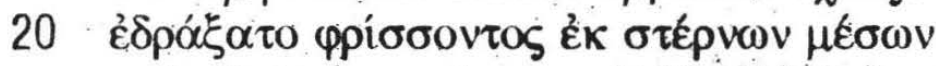

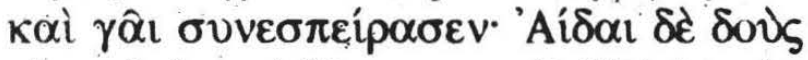

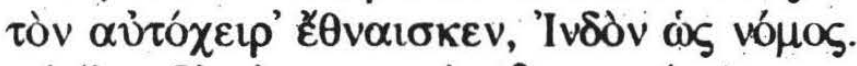

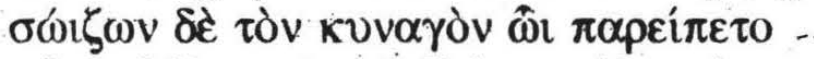

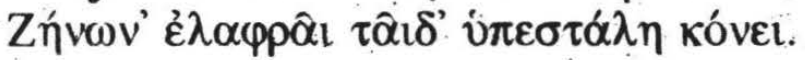

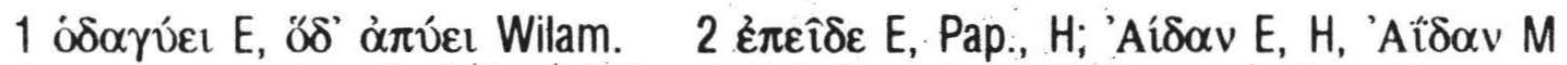

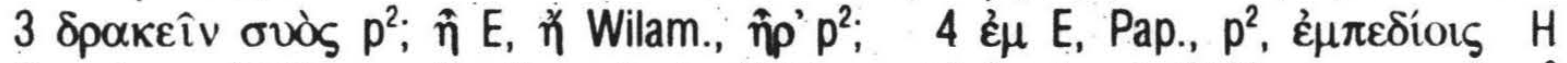

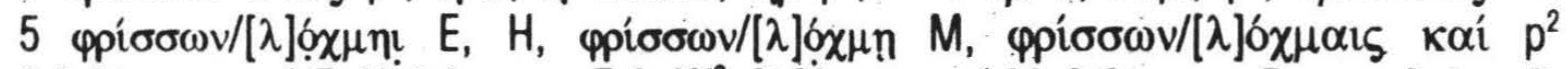

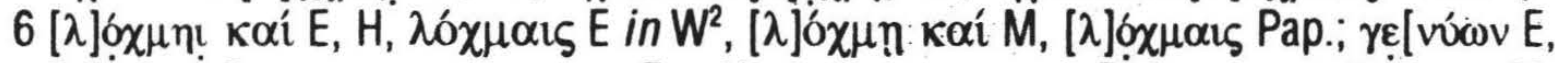

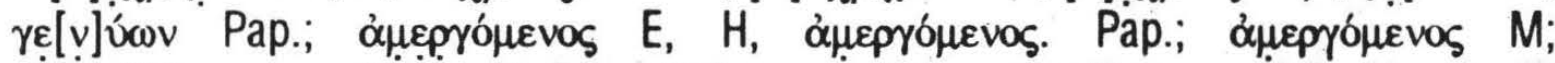

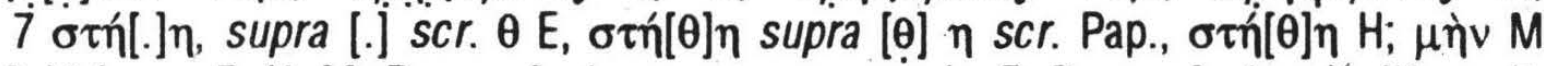

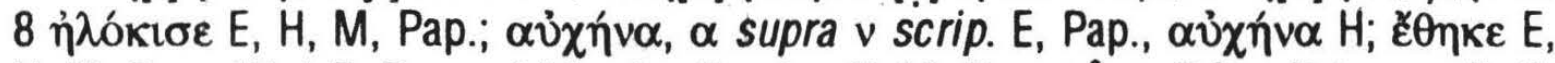

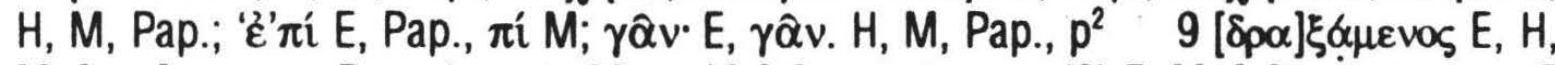

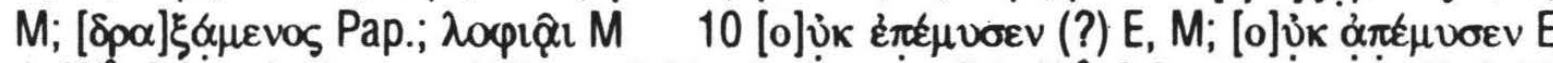

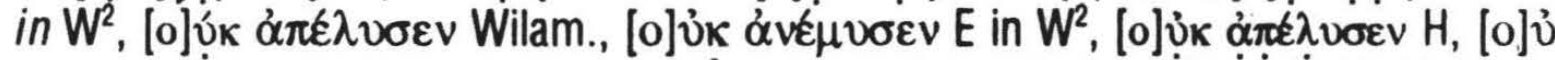

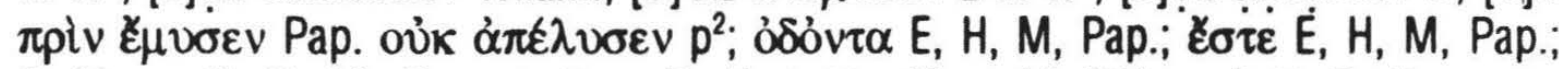

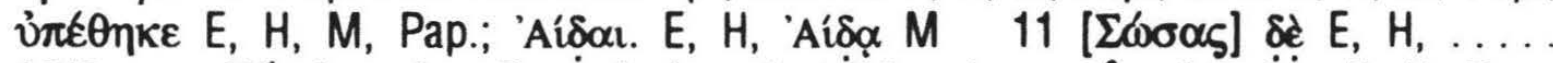

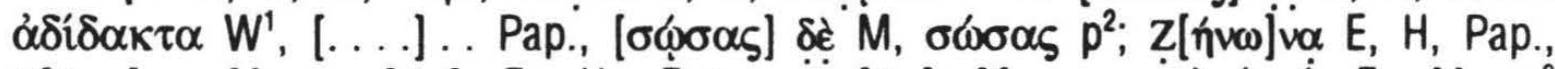

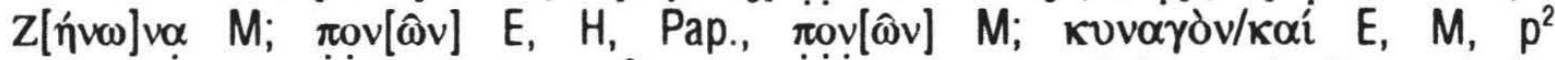

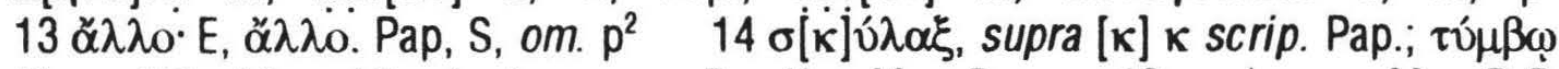

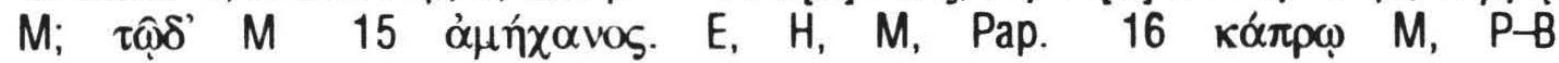




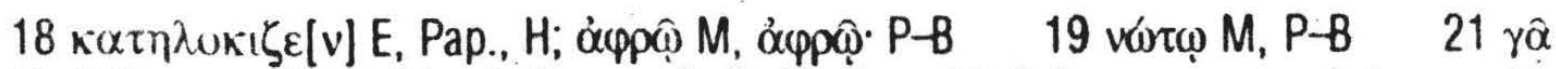

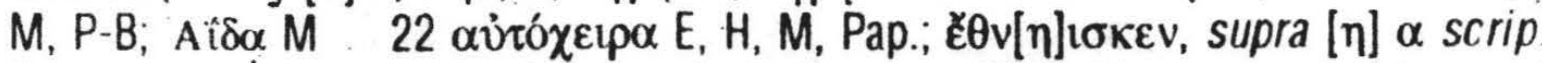

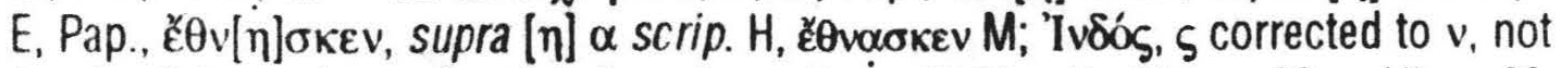

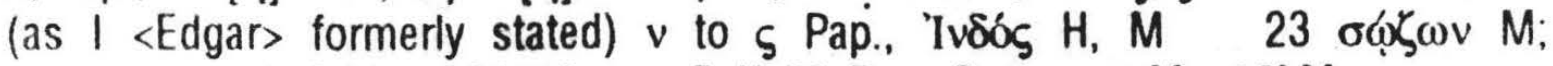

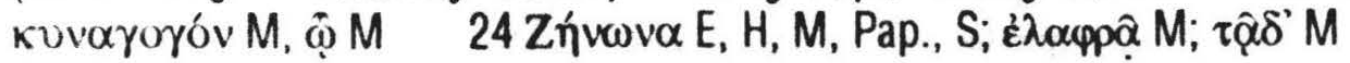

\section{TRADUCCIÓN}

Esta tumba proclama que el indio Taurón yace muerto, pero el que lo mató vio antes el Hades. Como una fiera (terrible) para mirar de frente o reliquia del cerdo de Calidón, se crió en las fértiles llanuras de Arsínoe, inflexible, erizándose todo desde el cuello en los matorrales y echando espuma por las mandíbulas. Lanzándose sobre la audacia del cachorro le abrió el pecho en surcos, pero éste, no hesitando, le puso el cuello en tierra, pues (el cachorro) tras agarrarle a su vez el gran tendón junto con la crin, no aflojó antes los dientes, hasta que lo envió al Hades. Y, aunque aún no entrenado, salva de los sufrimientos a Zenón, el cazador, y ganó la gratitud (de su amo) bajo la tierra, con esta tumba.

Otro.

Un cachorro está sepultado con honras fúnebres en esta tumba, Taurón, no sin recursos contra asesinos; pues cuando se encontró con un jabalí en lucha frontal, éste, como alguién inabordable, después de hinchar la mandíbula, le cortó en surcos el pecho, emblanqueciéndose por la espuma, y aquél, después de poner en torno del lomo las marcas de sus dos patas, agarró del medio del esternón al erizado (jabalí) y lo hizo rodar por tierra. Y tras dar al Hades al asesino, murió como la norma (manda) al indio: $Y$, salvando al cazador a quien acompañaba, a Zenón, está oculto por este ligero polvo.

\section{COMENTARIO}

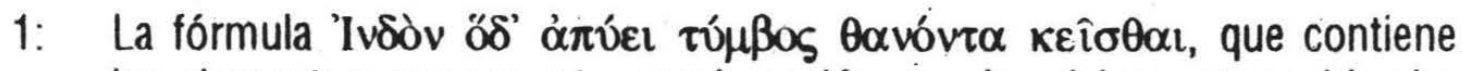
los elementos: monumento, proclamación, nombre del muerto y el hecho de que alli yace, es equivalente a la fórmula que inicia el epigrama de

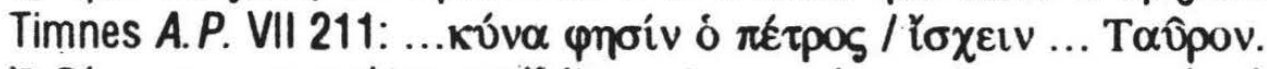

'Ivóóv: no se menciona explícitamente que el muerto sea un animal. Ello puede deberse a la intención del poeta de llamar la atención del pasante 0 , si había un relieve con la figura de un perro, no fue considerado necesario.

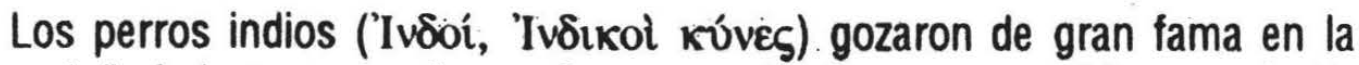
antigüedad: en gran número forman parte de una procesión organizada por Ptolomeo Filadelfo ${ }^{18}$ y se los encuentra en el ejército de Jerjes ${ }^{19}$; también, según Heródoto (I 192), cuatro grandes aldeas persas alimentaban a perros indios, por lo cual estaban exentas de cualquier otro tipo de tributo.

18. Ateneo V 196 ss.; quien cita el libro IV de la obra sobre Alejandría de Calixeinos de Rodas.

19. Hdt. VII 187. 
En cuanto a su origen 20 encontramos opiniones diversas: Aristóteles en su Historia Animalium (607 a 4 ss.) afirma que son producto de la cruza de tigre y perra - opinión que sigue Plinio 21 , pero en de Generatione Animalium (746a 29 ss.) los considera surgidos de la cruza de perra y de algún animal salvaje semejante al perro. Para Page 22 , quien sigue a Orth 23 y a Keller ${ }^{24}$, se trataría de un dogo tibetano. Según Richter 25 parecen identificarse con los molosos.

También varios autores nos hablan de sus cualidades: Jenofonte los describe como fuertes, de gran tamaño, rápidos y muy valientes (Cyn. IX 1). Según Ctesias 26 eran tan fuertes que podian luchar con un león 27. Jenofonte señala también expresamente que eran empleados en cacerías de ciervos (Cyn. IX 1) y de jabalíes (Cyn. X 1), en estas últimas junto con perros de otras razas.

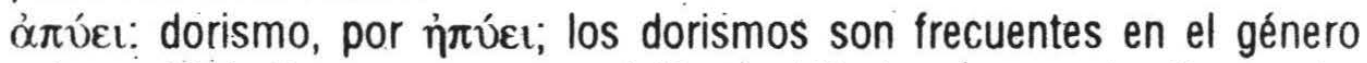
epigramático. En nuestra composición también lo son: $\pi \alpha \varsigma_{\varsigma}(v .3), \gamma \hat{\alpha} v(v$.

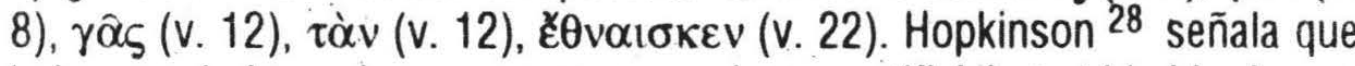
la lengua de los epigramas es una amalgama artificial, no el habla de una región en particular. El epigrama a la estatua de Arato ${ }^{29}$, p. ej., incluye:

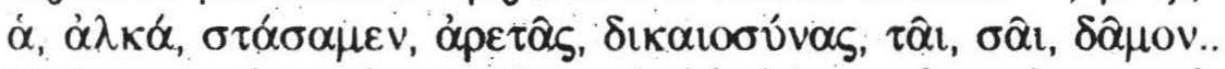

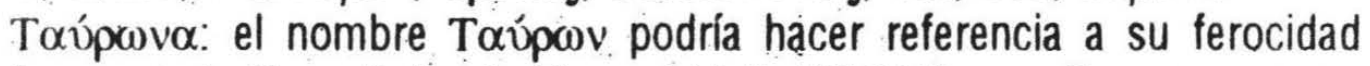

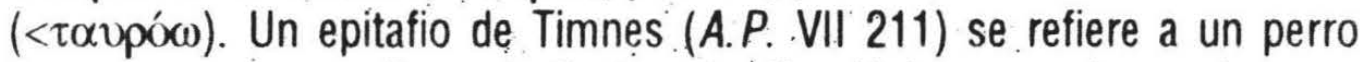
llamado Toûpos. Pero Antípater de Tesalóniça menciona al perro

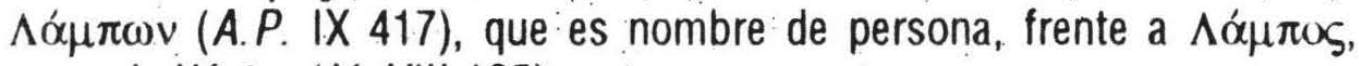
perro de Héctor (I1. VIII 185).

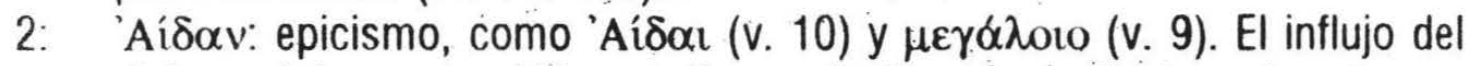
dialecto épico es también notorio en el género, no sólo formalmente por el uso del hexámetro, sino también por el tono elevado que suelen tener los epigramas, especialmente los funerarios. En la A.P. encontramos,

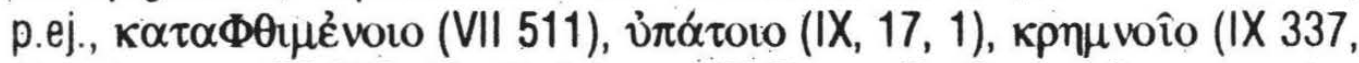

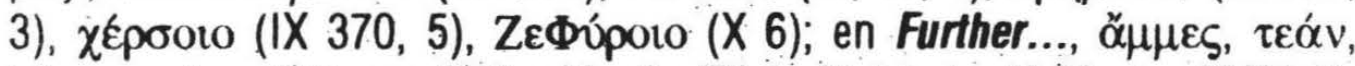

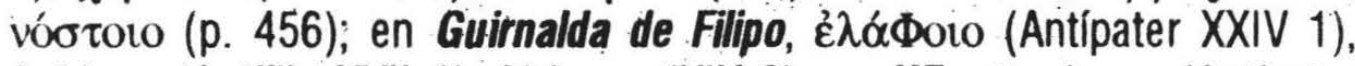

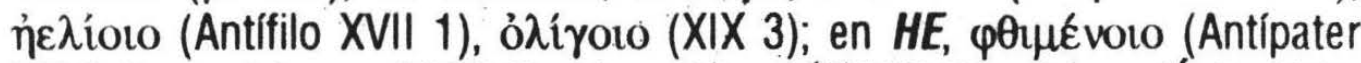

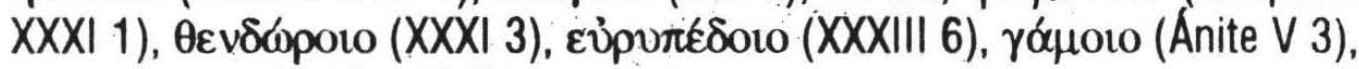
róppoto (Teodoridas III 1), etc.

20. Cf. Arthur Platt, "On the Indian Dog" , Q C. III (1909), pp. 241-243.

21. N.H VIII 148.

22 . Further ... p. 457.

23. RE 8, 2545.

24. Die Antike Tierwelt. Berlin, 1907-1920. I 109.

25. KI. Pauly, s. v. Hund

26. En Focio, Bibl. 45 b

27. Cr. Estrabón XV 31

28 . p. 274

29. Further

,p. 456 
3: K $\alpha \lambda v \delta \omega \hat{v o s: ~ E l ~ t e m a ~ d e ~ l a ~ c a z a ~ d e l ~ j a b a l i ~ d e ~ C a l i d o ́ n ~ a p a r e c e ~ y a ~ e n ~ l a ~}$ IIIada (IX 524 ss.), cuando se relata la historia de Meleagro: el jaball ( $\sigma 0 \hat{v}$ ă $\gamma$ prov), robusto, devastador 0 solitario (posibles interpretaciones de

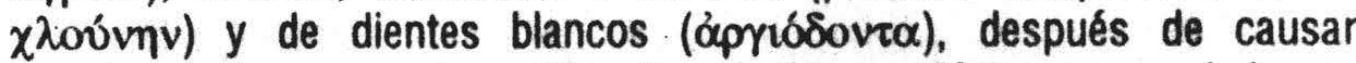
grandes destrozos y cobrar vidas, fue abatido por Meleagro, ayudado por cazadores y perros (кúvos). Surge luego una disputa por la cabeza y la

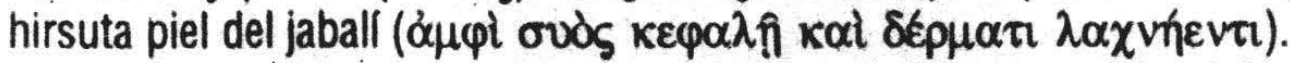

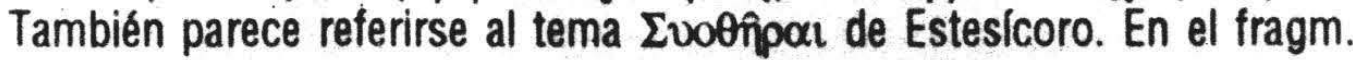

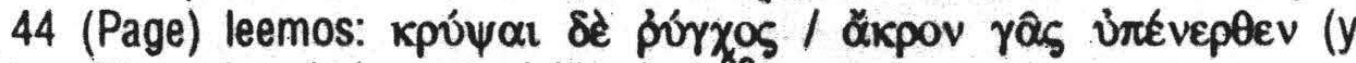
hundió en el suelo la punta del hocico) 30 .

5: 'Aporvóas: 'Aporvoît se encontraba Filadelfia, donde residia Zenón.

7, 14: También es $\sigma \kappa u ́ \lambda \alpha \xi$ la perra locria, asimismo recomendada para la caza de jabalies, cuya muerte canta Anite (HEX, p. 37).

11: hay incoherencia entre $\alpha \delta \delta \delta \alpha \kappa \tau \alpha$ (que no puede ser acusativo singular masculino ni femenino $y$, en todo caso, podría ser una forma de nominativo femenino) e 'Iuð́v (v. 1) y todos los participios

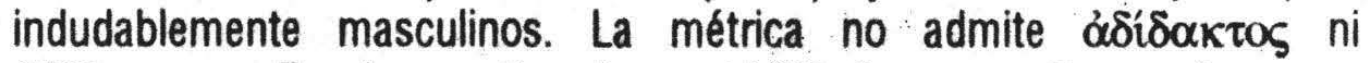
$\alpha \delta i \delta \alpha \kappa \tau o v$. ¿Es el acusativo de un ${ }^{2} \alpha \dot{\delta} \delta \delta \alpha \xi$, y se refiere entonces a Zenón, el cazador?

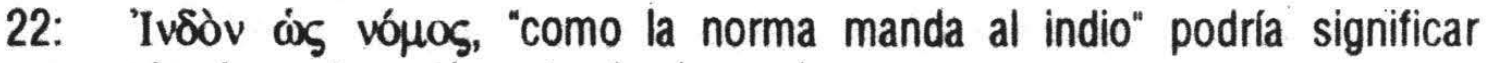
simplemente morir matando al enemigo.

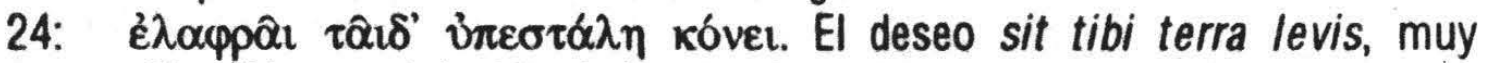
difundido en el ámbito latino, suele encontrase en el ámbito griego en epigramas de cierta extension y constituye por lo general el final (cf. GV $755,1512,1549)$.

Estos dos epigramas se inscriben, por su forma, dentro de la tradición del género. En la primera parte, o 'presentación', se precisa para quién fue erigida la tumba; en una segunda parte, los 'pormenores', se ofrece mayor información sobre el mismo.

Desde el punto de vista de la forma, la 'presentación' es diferente en ambas poesias. En la primera, la piedra informa en tercera persona el nombre del muerto: en una proposición de acusativo más infinitivo el sujeto es Taurón, el nombre, con un gentilicio como atributo, 'Iv $\delta 6 \mathrm{v}$; el atributo precede $\mathrm{y}$, en cierta manera, cumple la función de un pormęnor. En la segunda composición la presentación adquiere una expresión más personal. En primer lugar no hay verbo conjugado; tampoco hay una formula corriente, sino que leemos $\tau \hat{v} \mu \beta \omega r \tau \hat{\omega} \imath \delta^{\prime}$ vi $\pi^{\prime}$

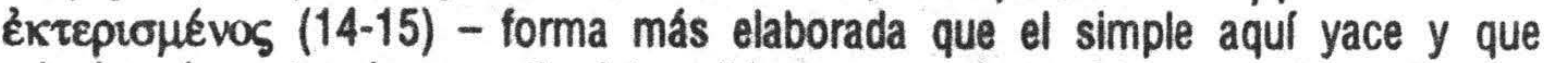
adquiere importancia a partir del s. IV-; enmarcada también por el nombre del muerto, en forma paralela a la primera poesia: precedida por $\sigma x u ́ \lambda \alpha \xi$ y seguida por

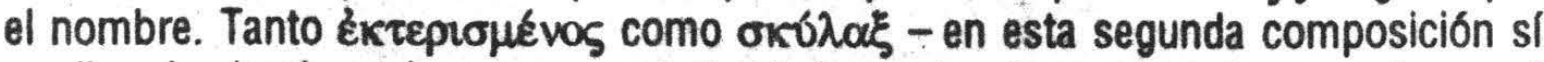
se dice desde el comienzo que se trata de la tumba de un animal - cumplen aquí también, en cierto modo, la función de pormenor.

Ambas presentaciones son completas en si mismas. A continuación siguen los pormenores. Sintácticamente están constituídos, en la primera poesía, 
por una proposición coordinada con la anterior; en la segunda, por un atributo del sujeto, o sea, del nombre del animal. Es decir, en la primera composición, presentación y pormenores constituyen dos unidades sintácticas, mientras que en la segunda están, desde el punto de vista de la sintaxis, estrechamente unidos.

Tradicionalmente en los pormenores se elogia al muerto o se lamenta su pérdida, es decir, se trata de transmitir de alguna manera a la posteridad por qué se debe conservar su memoria, qué areté especial ha demostrado en la vida y en la muerte. En ambos epigramas los pormenores - en este caso el destacar la valentía de Taurón, es decir, su areté guerrera - constituyen una alabanza del muerto y completan el segundo verso. Pero alabanza y lamento no son excluyentes, y así como el lamento lleva implicita una alabanza, la alabanza lleva implicito un lamento.

Con los dos primeros versos podría quedar concluido cada epigrama: se inscribirían asi en la tradicional y ampliamente documentada serie de composiciones de un solo distico. El mantenimiento del orden presentación - pormenores podría señalar una voluntad consciente de anudar con la tradición, ya que a partir del s. IV se vuelve común invertir dicho orden para lograr una mayor tensión.

En muchas composiciones tempranas los versos que siguen a los dos primeros son sólo una ampliación de ellos, se agregan para decir algo más, pero sin que la composición alcance una estructura unitaria total. En la primera composición esta parte no resulta lograda, en particular los versos 7 a 10, donde no hay una transición que haga claro el cambio de sujeto. En esta parte se presenta el componente narrativo que según Gentili ${ }^{31}$ se combina con el elemento trenódico.

Otro elemento de frecuente aparición en las inscripciones fúnebres es la mención explicita del dedicante, especialmente presente en el caso de una muerte temprana. En las composiciones de un solo distico suele integrarse en la presentación, confiriéndoles una mayor fuerza poética. Si bien en ninguna de las dos composiciones se dice explícitamente quién hizo erigir la tumba, se alude a él en ambas en forma indirecta en los dos últimos versos, al señalar qué la valiente actitud del cachorro salvó la vida de Zenón. Tampoco se menciona la muerte

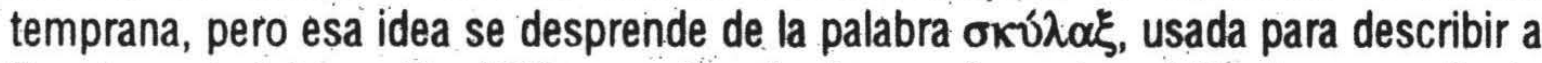
Taurón, y de la mención ó $\delta i \delta \alpha \kappa \tau \alpha$ (en el primer epigrama, v. 11), si es que ella se refiere al cachorro y no a Zenón.

Si comparamos con las características que Herrlinger enumera, observamos que sí se verifican los siguientes rasgos: la indicación de la edad (aquí por la palabra $\sigma \kappa u ́ \lambda \alpha \xi$ ); la causa de la muerte, fuera de lo comán; la composición en tercera persona, adecuada para animales grandes o feroces; la laudatio del muerto ( $\tau \delta \hat{\lambda} \mu \alpha \iota)$; el agradecimiento merecido, que justifica el poema y que sugiere, al igual que la mención del nombre del animal, su elevación de la mera condición de animal a la esfera de lo humano. También se incluyen giros de epitafios humanos

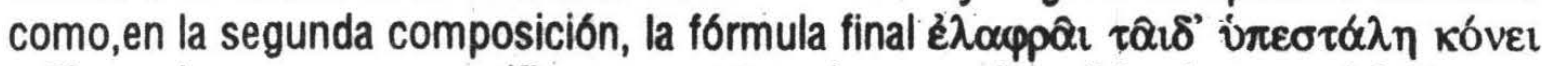
. Sin embargo, no se verifican en estos poemas el pedido de que el lector se conduela ni la disculpa originada en un posible sentimiento de ridiculez.

Los dos epigramas, aunque no muy valiosos, muestran motivos literarios conocidos: La lucha entre el perro y el jaball - característico de las épocas 
helenística y alejandrina ${ }^{32}$-el "ligero polvo" que cubre al muerto, las menciones del Hades, tan frecuentes en los epigramas.

Al contrario de lo que encontramos normalmente, no se utiliza la segunda parte en los dos epigramas para tratar distintos aspectos, sino que son variaciones de uno y el mismo tema, incluso con la repetición literal de algunas palabras, como

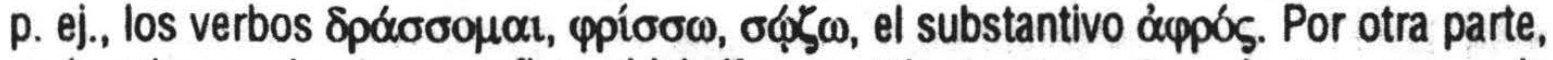
en la primera el autor se refiere al jaball como otp y como $\sigma 0 \hat{s}$, mientras que en la segunda lo llama ќ́x

Frente al hecho de que - según señala Lausberg - en el caso de composiciones paralelas lo habitual era que la segunda ofreciera mayores o diversas informaciones, rasgo que en nuestro caso no se observa, podría hacernos pensar que tan sólo una de estas composiciones debla ser elegida para el monumento concreto. Sin embargo, es cierto que en el epigrama literario y también en el subliterario es frecuente hallar variaciones de un mismo tema, lo cual puede sugerir que en ello se complacían tanto los dedicantes como los lectores. Tal, pues, podría ser el caso de los poemas que nos ocupan, donde para el segundo se elige el metro yámbico sin que lo requiriera, como en otros casos, el nombre del muerto o del dedicante.

Esperamos ofrecer un texto filológicamente más rico con un aparato crítico completo, que permitan al estudioso de la antigüedad valorar con más numerosos elementos de juicio esta obra de la producción literaria greco-egipcia.

\section{Biblogafafia}

Catalogue général des antiquités égyptiennes du Musée du Caire; Zenon Papyri, ed. C.C. Edgar. El Cairo, 1925-31, 4 vols. (P. Cairo Zen. IV 59532).

EDGAR, C. C. Annales du Service des Antiquités de l'Égypte 19 (1920), nº 48, pp. 101-104 (editio princeps).

GENTILI, B. "Epigrama ed elegia", L'épigrame grecque, Genève, Fondation Hardt, 1968 (Entretiens sur l'antiquité classique, vol. XIV) (Gentili).

GORTEMAN, C. "Sollicitude et amour pour les animaux dans l'Égypte grécoromaine", Chr. d'Ég 32 (1957) (Gorteman).

The Greek Antology - The Garland of Philip and some contemporary epigrams, ed. by A.S.F. Gow and D.L. Page. Cambridge, University Press, 1968. 2 vols. (Guirnalda de Fillpo).

The Greek Anthology - Hellenistic Epigrams, ed. by A.S.F. Gow and D. L. Page. Cambridge, University Press, 1965. 2 vols. (HE).

HERRLINGER, G. Totenklage um Tiere in der antiken Dichtung. Stuttgart: Kohlhammer, 1930 (Tübinger Beiträge zur Altertumswissenschaft; 8) (Herrlinger). 
HOPKInsoN, N. A Hellenistic Anthology. Cambridge, University Press, 1988 (Hopkinson).

LAUSBERG, M. Das Einze/distichon. Studien zum antiken Epigramm. München, Wilhelm Fink, 1982 (Studia et Testimonia Antiqua; 19) (Lausberg).

MANTEUFFEL, G. De opusculis graecis Aegypti e papyris, ostracis lapidibusque collectis. Warzawa, 1930. Appendix, n², p.200 (Manteuffel).

PACK, R. The Greek and Latin Literary Texts from Greco-Roman Egypt. Ann Arbor, The University of Michigan Press, 1965, n 1761.

PAGE, D. L. Greek Literary Papyri, I Poetry. London-New York, Heinemann, 1942, no 109 (GLP).

PAGE, D. L. Further Greek Epigrams. Cambridge et. al., Cambridge University Press, 1981, pp. 457-58 (Further...).

POWELL, J. U. and BARBER, E. A. New Chapters in the History of Greek Literature. Oxford, Clarendon Press, 1921, pp. 107-108 (Powell-Barber).

PREAUX, C. Les Grecs en Égypte d'après les archives de Zénon. Bruxelles, 1947.

SEIDER, R. Paläographie der griechischen Papyri. Band II: Tafeln. Zweiter Teil: Literarische Papyri. Stuttgart, Anton Hiersemann, 1970, nº 4, p. 40 y fig. 4, lám. 3 (sólo líneas 13-24) (Seider).

WILCKEN, U. Archiv für Papyrusforschung und verwandte Gebiete 6 (1920), $n^{\circ} 48$, pp. 453-454 (Wilcken ${ }^{1}$ ).

WILCKEN, U. Archiv für Papyrusforschung und verwandte Gebiete 7(1924), $n^{\circ} 48$, p. 80 (Wilcken²). 